\section{D01.2 AMONG MEN WHO HAVE SEX WITH MEN, PHARYNGEAL INFECTION CONTRIBUTES MORE TO POPULATION LEVELS OF GONORRHEA TRANSMISSION THAN URETHRAL INFECTION, RECTAL INFECTION, OR BOTH (AGAINST THE MOTION)}

H Hunter Handsfield*. University of Washington, Seattle, USA

10.1136/sextrans-2019-sti.3

Under the renowned transmission paradigm $\mathrm{Ro}=\mathrm{CD}_{\mathrm{C}}$, the reproductive rate of an infection $\left(R_{o}\right)$ may be $\geq 1.0$ - sufficient to sustain or raise prevalence in a defined population - despite a short duration of infectivity (D), if transmission efficiency (B) or the rate of transmission events (c) is sufficiently high. $B$ is substantial for urethral to pharyngeal transmission, and probably modest for pharynx to urethra. But is $ß$ for analingus - for pharyngeal to rectal infection or rectal to pharyngeal - sufficient to sustain prevalent infections at either anatomic site? Is $B$ for kissing high enough to contribute substantially to pharyngeal gonorrhea? Overall, is $B$ for pharyngeal gonococcal infection sufficient to account, directly or indirectly, for half or more of all gonorrhea in men who have sex with men (MSM)? This proposition flies in the face of a century of historical opinion and clinical observation, the anatomy of sex, and available data. As observed by Marcello Truzzi and famously popularized by Carl Sagan, extraordinary claims require extraordinary evidence, a standard not met by observations in a single clinic or metropolitan area or by mathematical models that may not account for confounding factors. While bidirectional transmission by fellatio is well documented and contributes to ongoing transmission in MSM, the transmission efficiency of gonorrhea by kissing, or by analingus for either rectal or pharyngeal infection (or by cunnilingus, in either direction) probably is insufficient to sustain prevalence. Indeed, if anal and vaginal sex magically disappeared as sexual practices, gonorrhea might disappear entirely in exclusively heterosexual men and women and would become uncommon in MSM, including those with high rates of partner change. Reject the proposition!

\section{PL01 - THE ROLE OF GENOMICS IN THE DIAGNOSIS AND MANAGEMENT OF STIS}

Monday, July 15, 2019 8:15 AM - 8:50 AM

\section{PL01.1 THE ROLE OF GENOMICS IN THE DIAGNOSIS AND MANAGEMENT OF STIS}

Helena Seth-Smith*. University Hospital Basel, Department of Clinical Bacteriology/ Mycology, Basel, Switzerland

\subsection{6/sextrans-2019-sti.4}

The diagnosis of sexually transmitted infections (STIs) is a prequel to treatment. The more accurate the diagnosis, the better the treatment that can be offered. From syndromic diagnosis, through species diagnosis, to data on antimicrobial resistance (AMR) mechanisms carried by the infectious agent, higher resolution means improved treatment. The speed at which this information can be gathered is also critical to the successful administration of appropriate treatment and patient compliance. With the continuing global rise in STI diagnoses, the observed danger of diagnostic escape, and the imminence of untreatable gonorrhoea, we need to understand the evolution of STIs and the selection pressures that they are under. Whole genome sequencing can contribute a great deal towards this. Genomics has given us many insights into the lifestyles and evolution of bacterial STIs, over long and short term. Genomic surveillance will always be necessary to decipher population dynamics and to characterise novel strains. Work on genital microbiota and metagenomics can provide information on mixed infections. The pressing question is whether genomics can be used to rapidly develop point of care diagnostic tests, enabling practitioners to provide the most appropriate care for their patients.

Disclosure No significant relationships.

\section{PLO2 - IDENTIFICATION AND MANAGEMENT OF COMPLICATED SYPHILIS}

Monday, July 15, 2019 8:50 AM - 9:25 AM

\section{PL02.1 IDENTIFICATION AND MANAGEMENT OF COMPLICATED SYPHILIS}

Christina Marra*. University of Washington, Seattle, USA

\subsection{6/sextrans-2019-sti.5}

While the course of syphilis can be complicated by involvement of virtually all organ systems, arguably the most difficult forms of complicated syphilis to identify and manage are those that involve the nervous system. In the pre-antibiotic era, all patients with syphilis, regardless of symptoms, underwent a lumbar puncture (LP), and those with cerebrospinal fluid abnormalities received augmented therapy in an effort to prevent subsequent symptomatic neurosyphilis. When penicillin became available, this practice seemed unnecessary. Subsequent reports of symptomatic neurosyphilis after appropriate treatment for early syphilis in persons living with HIV revived LP in neurologically asymptomatic individuals. However, its benefit in terms of morbidity averted is unknown, and recommendations have varied despite lack of data. In this presentation, complicated syphilis is defined as neurosyphilis, ocular syphilis, or otosyphilis. Topics to be discussed include epidemiology, host and bacterial risk factors, screening, the role of LP in management, and treatment.

Disclosure No significant relationships.

\section{PLO3 - ENGAGING INDIGENOUS COMMUNITIES IN HEALTH PROGRAMS}

Monday, July 15, 2019 9:25 AM - 10:00
AM

\section{PL03.1 ENGAGING INDIGENOUS COMMUNITIES IN HEALTH PROGRAMS}

Charlotte Loppie*. University of Victoria, Victoria, Canada

\subsection{6/sextrans-2019-sti.6}

Indigenous peoples and communities experience a disproportionate burden of STBBIs within specific historical, socio- 